\title{
Three Mile Island re-visited
}

\author{
Alan Cottrell
}

IN ApRIt. 1980 the New York Academy of Sciences, in its highly commendable role of providing an open forum for the discussion of scientific questions, held a conference on the nuclear accident at Three Mile Island and the lessons to be learned from it. The results have been brought together in this book, Vol.365 of the Annals of the New York Academy of Sciences, which reports the conference.

The meeting was opened by a keynote address from Alvin Weinberg. To him, the main lesson of TMI was that "the central problem of nuclear energy is not waste disposal or even the connection between proliferation and nuclear power. It is, rather, reactor safety". This gave him the text for an admirably wise and perceptive analysis of the main problems in making nuclear power not only safe, but also acceptable to the general public. Writing about the situation in the USA (which he contrasted strongly with that in the UK and Europe generally) he argued eloquently and persuasively: first, for consolidating the present highly fragmented US power utility industry into fewer organizations, each large enough to handle the farreaching responsibilities of reactor ownership and operation; and second, for putting power reactors all together in a small number of large and isolated sites, where they could be served by local communities who would be familiar, through their daily work, with nuclear energy. Weinberg thus called for a moratorium, not on new reactors, but on new reactor sites.

Many of the people who had been directly involved in the accident came to the conference and were able to give their personal views, as seen one year afterwards. Other participants, among whom were such familiar names as Norman Rasmussen and Chauncey Starr, included representatives of government and local authorities, the nuclear industry, the Nuclear Regulatory Commission (NRC), the President's Commission, universities and professional institutes, the media, public interest groups and residents of communities near Three Mile Island. They discussed many things: the technical history of the accident and the predicted likelihood of such an event; the amounts of radiation released and the problems, still to be solved, of decontaminating the site and removing safely the radioactive gases and water left in the buildings; the behaviour of the various individuals, organizations and authorities involved; the attitudes of the local inhabitants, some of whom remained
The Three Mile Island Nuclear Accident: Lessons and Implications. Edited by Thomas H. Moss and David I.. Sills. Pp.343. ISBN pbk $0-89766-116-8$. (New York Academy of Sciences: 1981.) $\$ 66$.

calm throughout, almost indifferent, whereas others suffered great mental distress.

A particularly lively part of the book deals with the acrimonious relations that have developed between the nuclear and public authorities and the press; the one side being accused of lying and concealing publically important information, the other of sensationalism, scare-mongering and cthical lapses. Whatever else TMI may have taught people, it has certainly exposed the atrocious state of communications between the nuclear industry and the general public via the media.

TMI was a Janus-faced accident, which told people what they wanted to know. To anti-nuclear people it showed how near the brink of public disaster the industry operates. To pro-nuclear ones it confirmed the safety of the system, which demonstrably protected the public from radiation injury and all physical hazard.

Everyone - myself included - learned their own lesson from TMI. Mine was that, when something goes wrong with the cooling system of a pressurized water reactor, the temperature and pressure can then change so suddenly as to impose an almost impossible burden of instant reaction on the reactor operators. The serious questions which this raises seem to me to have been dodged, perhaps because they may even raise doubts about the basic concept of high-pressure water reactors. Only Weinberg dares in this book to ask the ultimate question: whether one should reconsider other reactor systems - such as gas-cooled reactors - that depend less on engineered safety features and more on inherent characteristics to prevent accidents.

Sir Alan Coltrell, now Master of Jesus College, Cambridge, was previously the Chief Scientific Adviser 10 HM Government. His book, How Safe is Nuclear Energy?, was published by Heinemann Educational in June.

\section{Digital image processing moves on}

\section{P.W. Hawkes}

Two-Dimensional Digital Signal Processing. Edited by T.S. Huang. Part 1 Linear Filters, pp.230, ISBN 3-540-10348-1; Part 2 Transforms and Median Filters, pp. 230 , ISBN 3-540-10359-7. (Springer-Verlag: 1981.) Each Part DM 79, \$46.70.

AI THOUGH there is no reason why development in the sciences should fit neatly into decades, it is a fact that the 1970s, the first decade of digital image processing, were dominated by a certain type of thinking whereas a rather different approach seems likely to pervade the coming years. The beginnings of the subject were strongly influenced by the algebraic work of Andrews, Hunt, Pratt and others associated with the University of Southern California, by the statistical work of Frieden and by Rosenfeld and his school at the University of Maryland. The first two tendencies were well-documented in an earlier book edited by Huang, Picture Processing and Digital Filtering (for review see Nature 264, 142), which the present volumes complement. The two parts are very different: the first is devoted to twodimensional filters, both non-recursive (R.M. Mersereau) and recursive (two chapters, by P.A. Ramamoorthy and L.T. Bruton and by B.T. O'Connor and T.S. Huang) and to two-dimensional Kalman filtering (J.W. Woods). The second is concerned with methods of performing operations frequently needed in image processing - matrix transposition (J.O. Eklundh), convolution and the discrete Fourier transform (H.J. Nussbaumer), Winograd's algorithm (S. Zohar) - and also with median filtering, statistical (B.I. Justusson) and deterministic (S.G. Tyan).

The break with the work collected in Huang's earlier volume is most clearly seen in Part I. With the exception of the chapter on recursive filtering, all of that carlier book could be read without conceptual difficulty and with great profit by anyone concerned with images, whether his background was physics, applied mathematics or electrical engineering; the chapter on recursive filtering was distinctly less accessible, partly because the authors did not provide an introduction addressed 